\title{
Hypersonic Aerothermochemistry Duplication in Ground Plasma Facilities: A Flight-to-Ground Approach
}

\author{
Iş1 Şakraker,,$*$ Alessandro Turchi,, \pm and Olivier Chazot $\$$ \\ von Karman Institute for Fluid Dynamics, 1640 Rhode-St-Genese, Belgium
}

DOI: $\underline{10.2514 / 1 . A 33137}$

\begin{abstract}
High conservative safety margins, applied to the design of spacecraft thermal protection systems for planetary entry, need to be reduced for higher efficiency of future space missions. Ground testing of such protection systems is of great importance during the design phase. This study covers a methodology for simulating the complex hypersonic entry aerothermochemistry in a plasma wind tunnel for a given spacecraft geometry without any assumption on axisymmetry or bluntness. A demonstration of this proposed methodology is made on the Qubesat for Aerothermodynamic Research and Measurements on AblatioN, QARMAN mission, which is a rectangular reentry CubeSat with a cork-based ablative thermal protection system in the front unit. The reacting boundary-layer profiles of the hypersonic entry probe compare well with the ones developing at the stagnation region of the plasma test model, defined with the proposed flight-to-ground duplication method.
\end{abstract}

\section{Nomenclature}

$D a \quad=$ Damkohler number

$\mathrm{d} u / \mathrm{d} x$ or $\beta=$ velocity gradient, $\mathrm{s}^{-1}$

$h=$ total enthalpy per unit mass, $\mathrm{J} / \mathrm{kg}$

$K=$ Zoby constant, $\mathrm{kg} /\left(\mathrm{m}^{3 / 2} \cdot \mathrm{s} \cdot \mathrm{Pa}^{1 / 2}\right)$

$\mathrm{NDP}=$ nondimensional parameter

$\mathrm{Pr} \quad=$ Prandtl number

$p \quad=$ pressure, $\mathrm{Pa}$

$\dot{q}=$ heat flux, $\mathrm{W} / \mathrm{m}^{2}$

Re $\quad=$ Reynolds number

$R_{\text {eff }} \quad=$ equivalent sphere radius, $\mathrm{m}$

$R_{m} \quad=$ hemispherical model radius, $\mathrm{m}$

$u=$ velocity component in $x$ direction, $\mathrm{m} / \mathrm{s}$

$v=$ velocity component in $y$ direction, $\mathrm{m} / \mathrm{s}$

$v(\delta) \quad=\quad$ velocity at the finite thickness

boundary-layer edge, $\mathrm{m} / \mathrm{s}$

$\Delta \quad=$ shock stand-off distance, $\mathrm{m}$

$\Delta p \quad=$ dynamic pressure, $\mathrm{Pa}$

$\delta \quad=$ boundary-layer thickness, $\mathrm{mm}$

$\mu \quad=$ viscosity, $\mathrm{N} \cdot \mathrm{s} / \mathrm{m}^{2}$

$\rho=$ density, $\mathrm{kg} / \mathrm{m}^{3}$

$\tau=$ characteristic time, $\mathrm{s}$

Subscripts

$\begin{array}{ll}\text { chem } & =\text { chemical reactions } \\ D & =\text { dissociation } \\ e & =\text { boundary-layer edge } \\ \text { FT } & =\text { finite thickness } \\ \text { flow } & =\text { flow } \\ H & =\text { hypersonic } \\ S & =\text { subsonic } \\ S & =\text { torch exit }\end{array}$

Presented as Paper 2014-2567 at the 32nd AIAA Applied Aerodynamics Conference, Atlanta, GA, 16-20 June 2014; received 18 August 2014; revision received 1 July 2015; accepted for publication 2 July 2015; published online 9 September 2015. Copyright (C) 2015 by Isil Sakraker, Alessandro Turchi, and Olivier Chazot. Published by the American Institute of Aeronautics and Astronautics, Inc., with permission. Copies of this paper may be made for personal or internal use, on condition that the copier pay the $\$ 10.00$ per-copy fee to the Copyright Clearance Center, Inc., 222 Rosewood Drive, Danvers, MA 01923; include the code 1533-6794/15 and \$10.00 in correspondence with the CCC.

*Ph.D. Candidate, Aeronautics and Aerospace Department; isil.sakraker@ vki.ac.be.

†Postdoctoral Researcher, Aeronautics and Aerospace Department; alessandro.turchi@vki.ac.be. Member AIAA.

‡Professor, Aeronautics and Aerospace Department; chazot@vki.ac.be. $\begin{array}{lll}w & = & \text { wall } \\ 0 & = & \text { total conditions }\end{array}$

\section{Introduction}

O $\mathrm{NE}$ of the major goals of the aerospace research field is to increase the safety and the efficiency of the manned and unmanned space missions whether they travel to or from another planet or wander around the Earth. A very big challenge of such travels is the encounter with the atmosphere of a planet. When the spacecraft approaches the atmosphere with hypervelocity, it comes across a very harsh environment not only with a completely different stability regime than in continuum atmosphere and telecommunication blackout but also with extreme temperatures due to aerodynamic heating and exothermic chemical reactions at the wall. Hence, the spacecraft have to be protected by thermal protection systems (TPS). When designing and sizing TPS, material engineers must be very conservative to ensure the safety of the crew or the payload because the aerothermochemical environment and its physics are complex to be accurately predicted. This leads to inefficiently oversized designs with reduced available mass and volume budgets that would otherwise be used for propellant, payload, and scientific instrumentation.

The TPS is designed using numerical simulation (computational fluid dynamics [CFD] and material response codes) together with ground tests in facilities like arcjets, plasma wind tunnels, impulse facilities, and so forth. However, these designs based on simulation rely heavily on how accurately ground tests emulate the real flight conditions. This study presents a methodology to duplicate the flight environments in ground facilities for design and qualification purposes. It is applied to the design and testing of an atmospheric entry demonstrator: QubeSat for Aerothermodynamic Research and Measurements on AblatioN (QARMAN) [1].

The von Karman Institute (VKI) Plasmatron facility is taken as the ground-based facility for this study and its description is given in Sec. III. Because the test case reentry mission is on a CubeSat platform [2], it does not have a conventional aerodynamic design as described in Sec. IV C. This led to the need of a more detailed flightto-ground duplication methodology without any assumption on the spacecraft geometry.

\section{Literature Review}

\section{A. Local Heat Transfer Simulation}

The stagnation point heating of a vehicle flying at hypersonic velocities (Fig. 1) can be approximated by Eq. (1) from Fay and Riddell [3] : 


$$
\begin{aligned}
\dot{q}_{w}= & \left.0.763 \operatorname{Pr}^{-0.6}\left(\rho_{e} \mu_{e}\right)^{0.4}\left(\frac{\mathrm{d} u_{e}}{\mathrm{~d} x}\right)\right|_{\text {edge }} ^{1 / 2}\left(\rho_{w} \mu_{w}\right)^{0.1}\left(h_{0, e}-h_{w}\right) \\
& \times\left[1+\left(L e^{\alpha}-1\right)\left(\frac{h_{D, e}}{h_{0, e}}\right)\right]
\end{aligned}
$$

This form of the equation is valid for fully dissociated air and where Prandtl number is not necessarily equal to 0.71 . The exponent of Lewis number $\alpha$ is given as 0.52 for an equilibrium boundary layer and 0.63 for a frozen boundary layer with fully catalytic wall. The latter is suggested as 2/3 by Lees [4]. Goulard [5] suggested a similar heat flux equation for frozen boundary layer with arbitrary catalytic efficiencies at the wall and at any degree of dissociation:

$$
\dot{q}_{w}=0.664 \operatorname{Pr}^{-2 / 3}\left(\beta_{e} \rho_{e} \mu_{e}\right)^{1 / 2} h_{0, e}\left[1+\left(L e^{2 / 3} \phi-1\right)\left(\frac{h_{D, e} y_{e}}{h_{0, e}}\right)\right]
$$

where $y_{e}$ is the atom mass fraction at the boundary-layer edge and $\phi$ introduces the catalytic efficiency at the wall.

When Eqs. (1) and (2) are analyzed, it can be seen that the four independent parameters are the density $\rho$, the velocity gradient $\mathrm{d} u / \mathrm{d} x$, the total enthalpy $h_{0}$, and the composition at the boundarylayer edge. Assuming local thermochemical equilibrium (LTE) in the free stream, the density is a function of the pressure and the enthalpy; therefore, the heat flux is defined by three independent parameters, being the pressure, enthalpy, and the velocity gradient at the boundary-layer edge. This is called the local heat transfer simulation (LHTS) as developed by Kolesnikov [6]. Considering the stagnation region, if the pressure, enthalpy, and the velocity gradient at the boundary-layer edge of the vehicle are reproduced in the ground facility on a TPS sample, then the aerothermochemical environment is fully simulated. A sketch of the LHTS logic is given in Fig. 1 along with a zoom of the stagnation line quantities for the subsonic (ground testing) case.

At this point, it is important to stress that the velocity gradient parameter (referred to as $\beta$ from now on) requires a different attention than the pressure and enthalpy, which are characteristics of free stream only. It is defined as the derivative of the velocity component normal to the stagnation line, and it is strongly related to the vehicle geometry and the local flight conditions. It affects the convective characteristic time of the flow $\left(\tau_{\text {flow }}=\beta^{-1}\right.$ ) determining how fast the flow is deviated from stagnation region [3,7]. Therefore, recalling the definition of the Damkohler number, $\bar{D} \bar{a}=\tau_{\text {flow }} / \tau_{\text {chem }}$, it can be shown that $\beta$ is a key parameter to quantify how likely are the gasphase chemical reactions to occur. Furthermore, it is worth noting that the velocity gradient behavior depends on the flow regime. Figures 1 and $\underline{2}$ show the $\beta$ profiles for a subsonic and a hypersonic regime, respectively. From the qualitative point of view, the two curves exhibit a totally different behavior. In the subsonic regime the

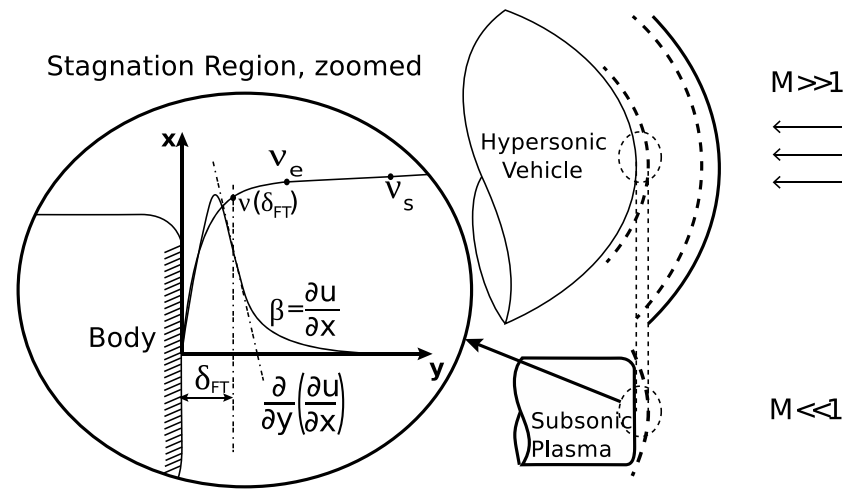

Fig. 1 LHTS approach (right). The velocity and velocity gradient $(\partial u / \partial x)$ profiles of a wall exposed to subsonic flow (left). The reference frame and vector convention assumed in this work are shown.

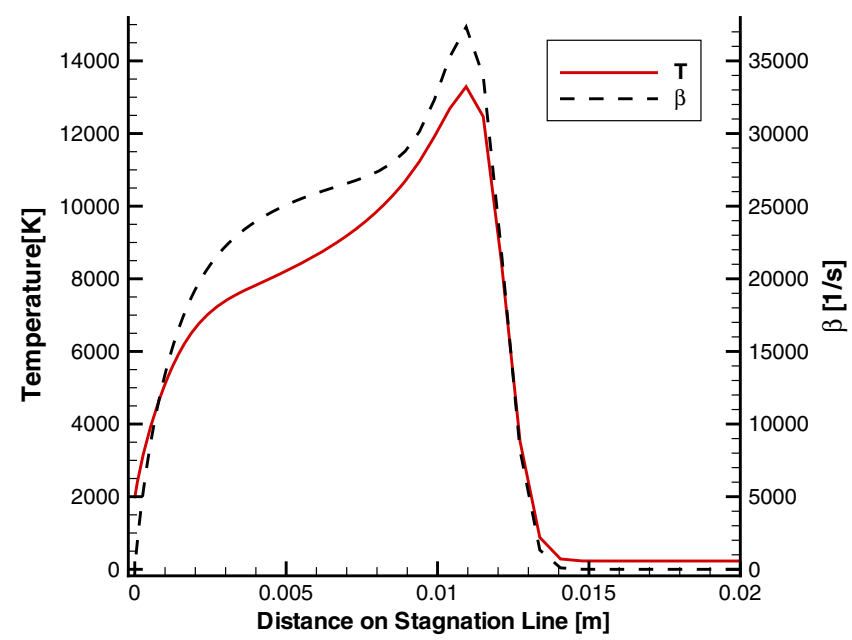

Fig. 2 Stagnation line temperature and velocity gradient profiles of QARMAN atmospheric entry at $66 \mathrm{~km}$ altitude. The hypersonic bow shock is at about $0.011 \mathrm{~m}$ from the wall.

velocity gradient asymptotically tends to zero upstream. In approaching the stagnation point, it rises up to a maximum value and then it goes to zero at the wall. Alternatively, in the hypersonic case it is null in the free stream, and it jumps to its maximum value right after the shock, and then decreases monotonically in the subsonic region.

The three parameters of LHTS are depicted in Fig. 3. The $\beta$ contours are computed, for a set of ground-facility free stream conditions and a single-probe geometry, using in-house ICP code [ 8 ] (further details on ICP code results are given in Sec. IV.C.3). It can be seen that each experimental point in the facility envelope corresponds to a different $\beta$. This suggests that a complete duplication of the flight stagnation-point heat flux can be achieved, provided that the right test pressure and enthalpy are chosen, only if the test sample is accurately sized to give a perfect matching of the $\beta$ parameter between the test and the flight. Figure 3 also shows the flight trajectory of the reentry vehicle QARMAN. It is straightforward to see that, unless the particular and unlikely situation for which a standard test sample shape always perfectly reproduces the flight vehicle $\beta$, adjustments of the test sample shape are required to test different trajectory points. Although QARMAN entry trajectory is given as example, the different probe geometry requirement stands for all entry vehicles (e.g., the case for Intermediate eXperimental Vehicle (IXV) vehicle is discussed in [9]).

For the characterization of TPS materials, the testing is conducted with standard probes that hold the test samples in the plasma wind tunnels with suitable instrumentation. These probes are sometimes referred to as Euromodel having a cylindrical flat-faced geometry with a body radius of $25 \mathrm{~mm}$ and a corner radius of $11.75 \mathrm{~mm}$ [10]. The testing conditions are specified with a stagnation pressure $\left(p_{0, e}\right)$

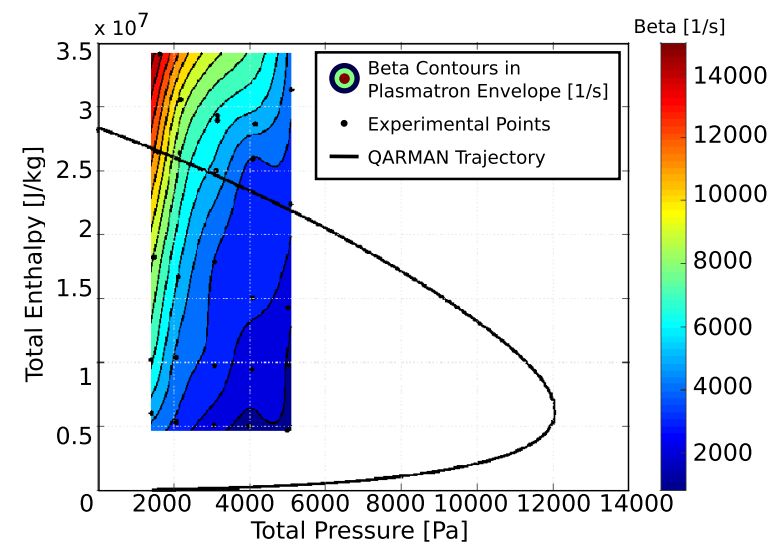

Fig. 3 The three LHTS parameters with QARMAN flight trajectory. 
and a total enthalpy $\left(h_{0, e}\right)$ on the probe geometry that defines the velocity gradient $(\beta)$ with the local flow conditions. From the quantities, one could perform the ground-to-flight extrapolation to determine the corresponding flight conditions and effective nose radius geometry that has been duplicated in plasma wind tunnel tests [11]. When one wants to follow the reverse process and to go from the flight conditions to the plasma wind tunnel testing, one will have to conduct a flight-to-ground duplication. This methodology should allow defining the probe geometry to duplicate the velocity gradient on ground respecting the total enthalpy and the stagnation pressure. The duplication is more involved than the previous one because the probe geometry should be determined from a velocity gradient in subsonic plasma flow environment for which no simple correlation exists as it could be found for hypersonic flows. As a result, a full CFD solution should be run with an iterative process as it will be explained in the following sections.

\section{B. Velocity Gradient Determination and Considerations}

Concerning the velocity gradient determination, theoretical and experimental analyses have been performed since 1950s, all for axisymmetric bodies. One of the easiest $\beta$ representation comes from the modified Newtonian theory (MNT) [7]. In this case, by making use of the one-dimensional momentum equation for the streamlines in the vicinity of the stagnation line, and using the sphere pressure distribution obtained from the Newtonian theory, the $\beta$ can be expressed as

$$
\beta_{e}=\frac{1}{R} \sqrt{2 \frac{\left(p_{e}-p_{\infty}\right)}{\rho_{e}}}
$$

The study of Boison and Curtiss includes experimental pressure measurements in the stagnation region of axisymmetric blunt bodies at supersonic Mach numbers [12]. They compare their experimental results to a combination of the $\overline{\mathrm{MNT}}$ and Bernoulli equations. A series of blunt shapes, consisting of spherical segments with varying radii and common cylindrical afterbody of radius $r^{*}$, was analyzed. Defining $x^{*}$ as the axial distance between the stagnation point (on the spherical segment) and the beginning of the afterbody cylinder, they found that for body configurations with high bluntness $\left(x^{*} / r^{*}<0.25\right)$ the MNT no longer applies if the nose radius is directly used in Eq. (3). This study was extended by Trimmer and Clark [13] to hypersonic flows on axisymmetric models with changing bluntness, and reached the same conclusion. Fletcher and Playez [14] use the velocity gradient scaling coefficients of Trimmer and Clark for hypersonic and subsonic flows as given in [15] for a blunt yet axisymmetric body and compared hypersonic and subsonic ground test facility measurements.

Models based on more accurate flow descriptions than Newtonian theory were presented over the years to address the problem of the $\beta$ determination. The equation of Lunev is slightly different from MNT and is based on thin shock layer theory [ㅌ]:

$$
\beta_{e}=\frac{1}{R} \sqrt{\frac{8}{3} \frac{\left(p_{e}-p_{\infty}\right)}{\rho_{e}}}
$$

The study of Olivier [17] has mass and momentum equations written in polar coordinates for a sphere starting from a general expression as stated in the book by Hayes and Probstein [18], in which real gas effects, vorticity behind the detached shock, and compressibility effects are considered. As a result, the velocity gradient expression is driven as follows:

$$
\beta_{e}=\frac{1}{R} \frac{(1+\bar{\Delta})}{\bar{\Delta}} \frac{p_{0,2}-p_{2}}{\rho_{\infty} u_{\infty}} \frac{\rho_{0,2}}{\rho_{s}}
$$

where the subscript 2 corresponds to the conditions after the shock, and $\bar{\Delta}=\Delta / R$ is the normalized shock standoff distance. For further reading on other studies using this approach, see [16, 19-22]
Several mission-oriented velocity gradient scaling approaches, all for spherical-nosed axisymmetric vehicles, as the one presented in [23] for the Hayabusa capsule or the one used in [24] in the full-scale testing approach of the small capsule SPRITE for supersonic arcjet testing, were used in the past. However, these approaches always apply to spherical-nosed axisymmetric vehicles. A practical different example is the design of QARMAN vehicle and its thermodynamic payloads. The unconventional rectangular prism shape of QARMAN required a specific study to assess a suitable approach for determining the velocity gradient in case of a nonaxisymmetric and nonspherical body. In the case of QARMAN the bluntness is 0.1 and so, according to the work of Boison and Curtiss [12], the nose curvature radius of $23 \mathrm{~cm}$ cannot be used directly to compute the $\beta$ value through Eq. (3). However, although Eqs. (3-5) are functions of the radius $R$ that is of a sphere, they can be still valid if an effective radius $R_{\text {eff }, H}$ is used instead of the nose curvature radius. Therefore, with the final objective of defining a hemispherical test sample radius to allow the $\beta$ duplication in the ground facility, and so the stagnation-point heat flux reproduction, the problem turns into the computation of the effective radius $R_{\text {eff, } H}$ [by inverting one of Eqs. (3-5)], provided that the $\beta$ value in the flight conditions is known. Unfortunately, the extraction of $\beta$ directly from hypersonic numerical solution is not trivial because the boundary-layer edge is not evident to determine as depicted previously in Fig. 2. The following sections discuss a methodology that is considering all the aspects mentioned above and its application on squared geometry QARMAN using Eq. (4) formulation that is also used by Kolesnikov [6].

\section{Plasmatron Measurements and Uncertainty Characterization}

As stated previously, the scope of this study is the improvement of the ground testing pertinence and accuracy of the VKI Plasmatron facility [25]. The Plasmatron facility is a high-enthalpy wind tunnel in which a subsonic plasma jet is generated by electromagnetic induction inside a test chamber at subatmospheric pressure (between $10 \mathrm{mbar}$ and $1 \mathrm{bar}$ ). The facility uses a high-frequency, high-power, high-voltage ( $400 \mathrm{kHz}, 1.2 \mathrm{MW}, 2 \mathrm{kV}$ ) solid-state (MOS technology) generator, feeding the single-turn inductor of the 160-mm-diam plasma torch.

For the subsonic plasma jet, the static pressure in the test chamber is measured with a high accuracy of $2 \%$ sensor error. The dynamic pressure is determined by differentiating mechanically the total pressure measured by a Pitot probe and the static pressure port in the test section. Its magnitude is very low compared with the static one. For a generic testing condition of $10^{4} \mathrm{~Pa}$, the resulting dynamic pressure is about $0.1-0.2 \%$ of the static pressure. The measurement error on dynamic pressure has been evaluated $15 \%$ through the measurement chain. Although its effect for total pressure determination is negligible, its contribution to the presented procedure can be important and is discussed in Sec. V.D.

The enthalpy at the boundary-layer edge can be rebuilt iteratively after the experiments using the VKI in-house rebuilding code (CERBOULA [26]) by heat flux and pressure measurements at the exact location where the TPS samples are tested. The boundary-layer edge enthalpy is determined through matching the edge temperature $T_{e}$. The uncertainty of this method is computed by a detailed uncertainty quantification study by Villedieu et al. [27]. In this work, an uncertainty of $6.3 \%$ is given for reference copper catalycities higher than 0.1. For values lower than 0.1 the uncertainties become larger. Panerai [9] at Plasmatron and Nawaz et al. [28] show that the copper catalycity for the reference condition is lower than 0.1 . Therefore, this conventional method is ruled out for the reference condition of this study.

The enthalpy is also measured using optical emission spectroscopy in which the line of sight is placed at the predicted boundary-layer edge by numerical simulation of the test chamber. The experimental method consists of measuring the spectral radiance of the excited oxygen triplet at $777 \mathrm{~nm}$. The spectral emission is then rebuilt through Abel inversion and straightly related to a temperature assuming LTE [29]. Knowing the pressure and temperature, the 
thermodynamic properties of the gas mixture at equilibrium can be then computed, including enthalpy. The applicability of LTE is limited by Plasmatron operating conditions. For the test case considered in this study, LTE can be assumed according to [30], where the electron densities are measured and compared with the Griem threshold [29]. The accuracy of the measurements is estimated to be $7 \%$. This method is chosen as reference having better accuracy than the numerical one. Its uncertainty is considered double the magnitude in the sensitivity analysis in Sec. V.D for conservation.

\section{Flight-to-Ground Duplication Methodology}

\section{A. Overview}

This section summarizes the proposed methodology, which is detailed in Sec. IV.C. The work logic of the proposed iterative approach for a correct velocity gradient duplication is presented in Fig. 4 . The procedure starts by computing the flight conditions of the vehicle along its atmospheric entry trajectory. An equivalent sphere flying at hypersonic velocities is defined by the stagnation line properties of the computed flight trajectory. An equivalent hypersonic sphere has identical stagnation line profiles with the actual entry vehicle and is unique for a given altitude and vehicle, thus changing along the trajectory together with the free stream parameters given in above equations. Next, an equivalent subsonic sphere is defined for the subsonic plasma flow. The subsonic equivalent sphere has the same stagnation region aerothermochemistry as the hypersonic vehicle and the equivalent hypersonic sphere. Using the equivalent subsonic sphere, the model geometry for the plasma wind tunnel conditions is determined. To do so, the boundarylayer models used for computations are adapted according to the appropriate Reynolds number regime in the test facility. Finally, an iterative process takes place for converging the computed ground test conditions and the model geometry found from the procedure.

\section{B. Boundary-Layer Approach for Stagnation Flow}

Before going further with the application of the proposed methodology, the first step is to demonstrate that a boundary layer could be defined around the stagnation point, at hypersonic conditions, in terms of the classical boundary-layer model at the stagnation line [31]. Therefore, computations from a full NavierStokes solver and a classical boundary-layer equation solver are compared having the same boundary conditions. Commercial CFD+ + code, which solves Navier-Stokes equations, is run for the 3D QARMAN geometry for the conditions at $66 \mathrm{~km}$ altitude of its reentry trajectory. The computations are initially done, assuming thermal equilibrium and chemical nonequilibrium with a 7-species air model [32], for a noncatalytic wall in radiative equilibrium. Then, the boundary-layer thickness is defined by a temperature linearity method that is discussed in the next chapter and the edge conditions at this point are taken from the stagnation-line solution of this calculation. These conditions, together with the obtained surface temperature, are given as boundary conditions to the VKI in-house boundary-layer code NEBOULA [26].

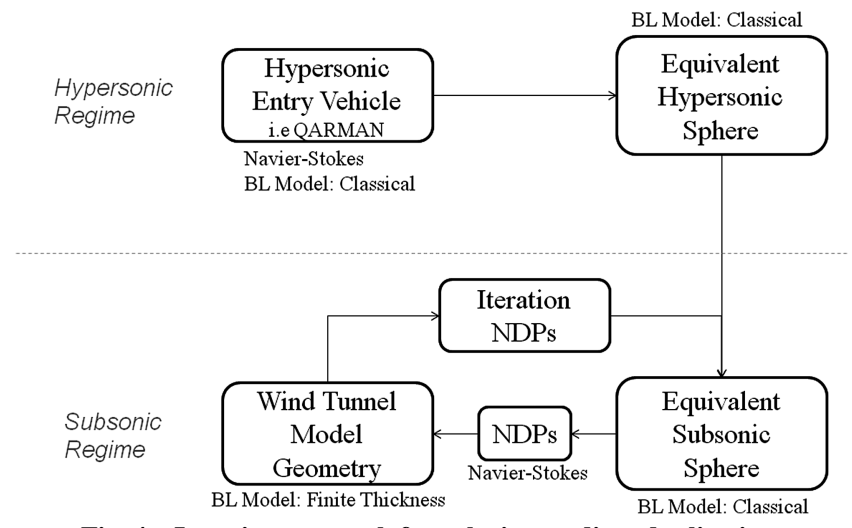

Fig. 4 Iterative approach for velocity gradient duplication.

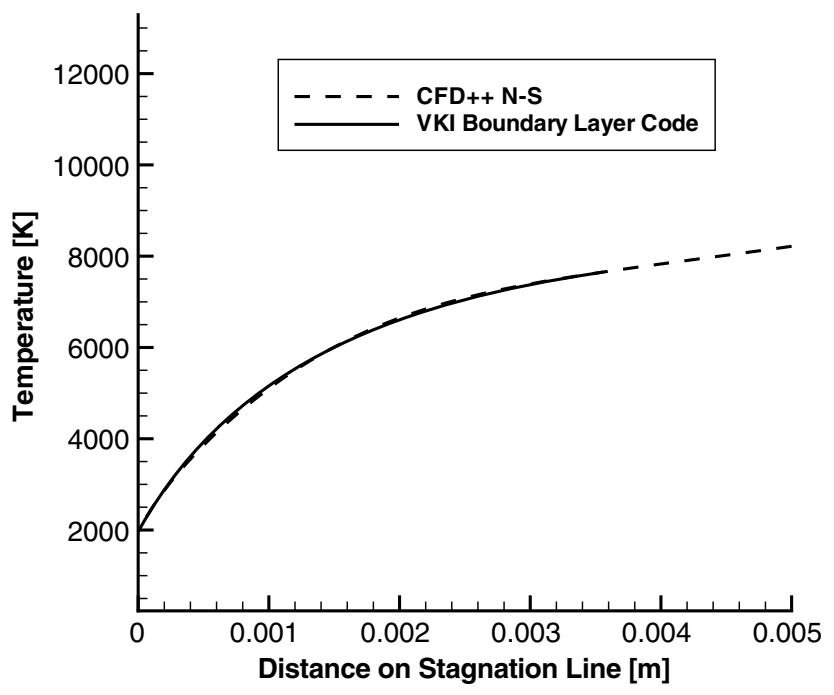

Fig. 5 Stagnation line temperature profiles comparison of NavierStokes solver (CFD++) and boundary-layer solver (NEBOULA) for QARMAN trajectory at $66 \mathrm{~km}$ altitude.

Figures $\underline{5}$ and $\underline{6}$, respectively, show temperature and density profile comparisons between the two codes. The two solutions show a very satisfactory agreement, and the profiles are practically superimposed through the boundary layer. The species concentrations, not shown here, are also in a very good agreement. Thus, one can treat the stagnation flow with parabolic boundary-layer formulation. What is interesting to see is that, on the stagnation line, the profiles do not behave asymptotically as the generic boundary-layer profiles on walls.

\section{Application to QARMAN: A Test Case}

QARMAN is a triple-unit (3U) CubeSat: a rectangular prism of $3 \mathrm{~kg}$ with dimensions $34 \times 10 \times 10 \mathrm{~cm}^{3}$. It has a cork P50 ablative thermal protection material at the nose and ceramic-based material on the body. It will perform an atmospheric entry representative of bigger scale missions with $7.7 \mathrm{~km} / \mathrm{s}$ at $120 \mathrm{~km}$ with a peak heat flux of $2.6 \mathrm{MW} / \mathrm{m}^{2}$ [1]. The rectangular prism shape comes from the CubeSat standards and its flexibility on launch opportunities [2]. Therefore, the challenge is to perform aerothermodynamic experiments on such geometry. The objectives of the in-flight experiments are to retrieve real flight data on ablator efficiency (temperature, pressure, recession) and temperature/pressure/skin

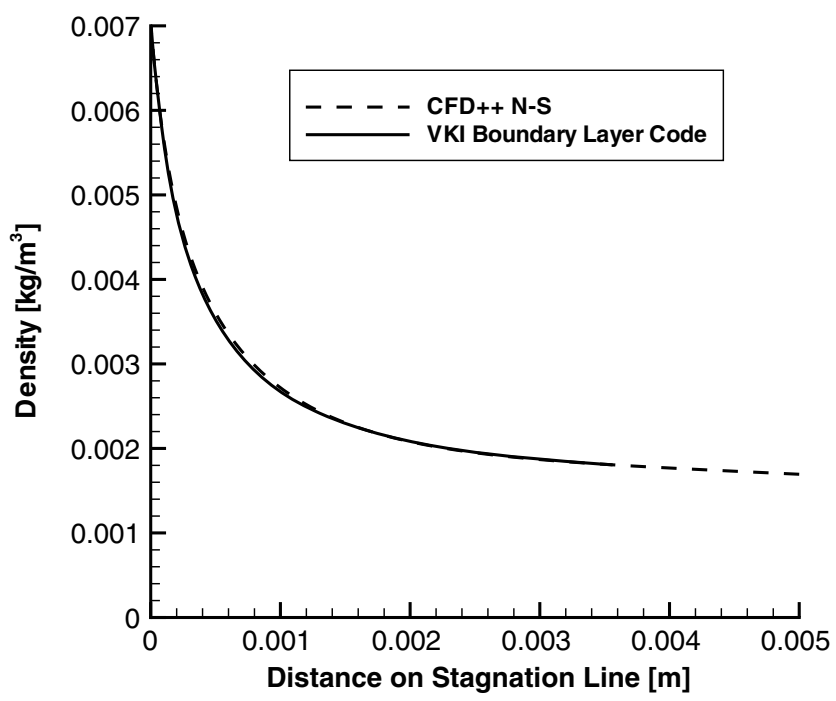

Fig. 6 Stagnation line density profiles comparison of Navier-Stokes solver (CFD++) and boundary-layer solver (NEBOULA) for QARMAN trajectory at $66 \mathrm{~km}$ altitude. 


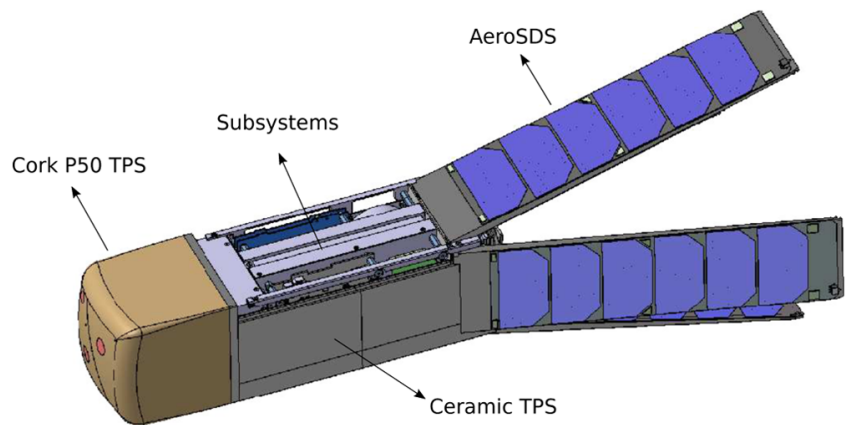

Fig. 7 QARMAN vehicle overview with its cork-based front TPS and ceramic-based side TPS. The nose radius of curvature is $23 \mathrm{~cm}$ and the corner radius is $1.2 \mathrm{~cm}$.

friction measurements for transition on the side panels. The stabilization and de-orbiting maneuver will be performed by AeroSDS, the opening panels shown in Fig. 7. Overall, this challenging mission targets to contribute to atmospheric entry research with nano- and picosatellite technology offering a very flexible system with good launch opportunities and reduced costs.

\section{Part 1: QARMAN Geometry to Hypersonic Equivalent Sphere}

A 3-D numerical aerothermodynamic database was computed for the entire vehicle trajectory. This computationally expensive analysis was carried out omitting any aspects related to the ablative TPS used in the QARMAN mission (vehicle shape change, pyrolysis gas blowing effect on attitude, etc.). A more detailed analysis would consider these aspects to quantify their effects on the aerothermodynamic database generation. However, the virgin shape of the vehicle was considered suitable for the purpose of the present analysis, which intends to describe the development of the flight-toground duplication methodology. It is also important to stress that the presented methodology should not be affected by the gas surface interaction phenomena. Turchi et al. [33] show in fact that the LHTS methodology can be applied even in the presence of ablation. The test case presented here corresponds to a $66 \mathrm{~km}$ altitude along QARMAN's entry trajectory computed with a noncatalytic surface with a radiative equilibrium boundary condition applied at the TPS surface. The free stream conditions are $V_{\infty}=6845.59 \mathrm{~m} / \mathrm{s}, P_{\infty}=$ $8.66 \mathrm{~Pa}, \rho_{\infty}=1.32075 \times 10^{-4} \mathrm{~kg} / \mathrm{m}^{3}$, and $T_{\infty}=228.925 \mathrm{~K}$ at $t=716 \mathrm{~s}$.

To apply the LHTS, the effective radius as presented with different approaches in Sec. II.B needs to be determined. To do so, one has to define the velocity gradient at the edge of the boundary layer. The approach is to select the point where the temperature profile stops to be linear after the shock. The relevance of this approach can then be confirmed by verifying that the selected point corresponds to the location where the velocity gradient computed for an inviscid case defers from that of a viscous case.

Once the velocity gradient is picked up, among the many options, the Lunev formula, given in Eq. (4), is the adopted one to compute the $R_{\text {eff }, H}$ as used by Kolesnikov [6] and Loehle et al. [23].

\section{Part 2: Hypersonic Equivalent Sphere to Subsonic Equivalent Sphere}

This step is where we pass from hypersonic to subsonic regime according to the operation mode of the VKI Plasmatron. Thus, the aim is to find the radius of a subsonic sphere that is equivalent to the hypersonic sphere found in the previous step.

Applying Eq. (1) for the hypersonic and subsonic cases, one could notice that total enthalpy, total pressure, and velocity gradient should be respected in both regimes, to retrieve the same total heat flux at the surface. It is important to note that the convective heat flux and the diffusive flux are also exactly reproduced in both regimes. The major difference in applying the heat transfer equation for the two cases is the expression of the velocity gradient because the pressure distributions around the stagnation point in both situations are expressed with different models.
The stagnation point heating equation by Fay and Riddell [Eq. (1)] can be reformulated for hypersonic flows as following, given by Zoby [22]:

$$
\dot{q}_{w} \sqrt{\frac{R_{\mathrm{eff}, H}}{p_{0}}}=K_{H}\left(h_{0, e}-h_{w}\right)
$$

where $K_{H}$ is

$$
K_{H}=\frac{0.763 P r^{-0.6} A^{0.5} 2^{0.25}}{R_{\mathrm{eff}, H}^{0.25}}\left(\frac{\rho_{w} \mu_{w}}{\rho_{e} \mu_{e}}\right)^{0.1}
$$

where $A$ is a constant coming from Sutherland's law of viscosity. The velocity gradient parameter in Eq. (1) can also be analytically evaluated for subsonic flow combining potential flow theory and Bernoulli's law for a sphere of radius $R_{\text {eff, } S}$. The pressure $p$ over a sphere is given by potential flow theory [34] as

$$
p=p_{e}-\frac{9}{4} \sin ^{2} \theta\left(p_{e}-p_{\infty}\right)
$$

Starting from Bernoulli equation, like Boison and Curtiss [12], one can differentiate the velocity $u$ with respect to $x$ to obtain an expression for velocity gradient. Assume that $x$ is the curvilinear abscissa that follows the surface starting at the stagnation point and $\theta$ is the angle between the stagnation point and a given point $x$ on the surface (see Fig. 1). At the stagnation region, $\theta$ is very small and so $x=R_{\text {eff }, s} \theta$ holds. Thus,

$$
\beta_{e}=\frac{\mathrm{d} u}{\mathrm{~d} x}=\frac{3}{2} \frac{1}{R_{\mathrm{eff}, S}} \sqrt{\frac{2 p_{e}}{\rho_{e}}\left(1-\frac{p_{\infty}}{p_{e}}\right)}
$$

Introducing Eq. (8) in the above equation and replacing the velocity gradient term in Eq. (1), one can obtain the following expression:

$$
\dot{q}_{w} \frac{\sqrt{R_{\mathrm{eff}, S}}}{\sqrt[4]{p_{e} . \Delta p}}=K_{S}\left(h_{0, e}-h_{w}\right)
$$

where

$$
K_{S}=\frac{0.763 P r^{-0.6} A^{0.5} 2^{0.25} \sqrt{3 / 2}}{R_{\mathrm{eff}, S}^{0.25}}\left(\frac{\rho_{w} \mu_{w}}{\rho_{e} \mu_{e}}\right)^{0.1}
$$

The $K_{H}$ and $K_{S}$ parameters include the terms given in Eq. (1) except the velocity gradient at the boundary-layer edge $\mathrm{d} u_{e} / \mathrm{d} x$. It is seen that the velocity gradient is expressed as a function of a spherical radius and pressure quantities in both hypersonic and subsonic cases. The parameters $K_{H}$ and $K_{S}$ are shown to be equivalent in hypersonic and subsonic regimes from the experiments conducted in many hypersonic ground test facilities and subsonic plasma wind tunnels [35]. Figure 8 shows a number of numerical and experimental data from subsonic and hypersonic facilities where the slope corresponds to the parameter $K$ in Eqs. (6) and (10) $[22,36-42]$.

Using the two expressions in Eqs. (6) and (10), a relation between the hypersonic and subsonic effective radii is deduced as follows:

$$
R_{\text {eff,Subsonic }}=R_{\text {eff,Hypersonic }} \times \frac{\sqrt{p_{e} \Delta p^{\text {ground }}}}{p_{0, e}^{\text {flight }}}
$$

\section{Part 3: Subsonic Equivalent Sphere to Model Geometry}

The plasma flow in the Plasmatron chamber impinging on a probe is numerically simulated at VKI by the in-house code ICP []. It simulates the equilibrium conditions in the chamber starting from the inductively coupled torch until the downstream of the sample by solving steady Navier-Stokes equations and accounting for the Joule effect, the Lorentz force caused by the magnetic field, and the 


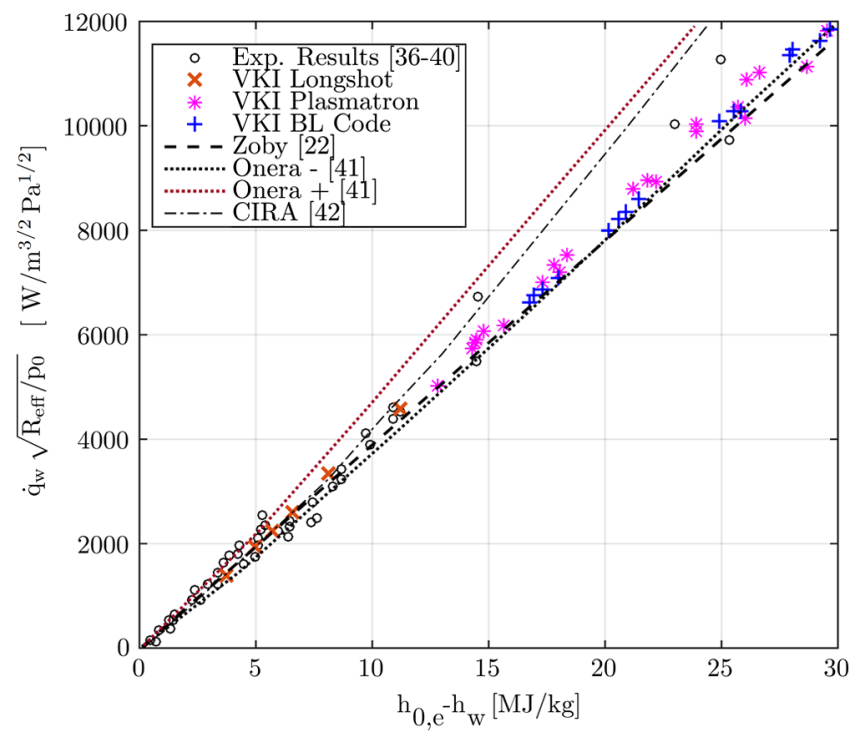

Fig. $8 K_{S}$ and $K_{H}$ parameters from subsonic and hypersonic wind tunnels. The plot is extracted from [35].

magnetic induction. The probes that are used in the Plasmatron are usually hemispherical-nosed cylinders. Two examples of ICP computations are shown in Fig. 9.

Recall that the $R_{\text {eff }, H}$ is found using classical boundary-layer theory (which was shown to be equivalent to Navier-Stokes solutions in Sec. IV.B) and so is the passage from $R_{\text {eff, } H}$ to $R_{\text {eff, } S \text {. The classical }}$ boundary-layer model is suitable for high Reynolds number flows [31]. However, the plasma flow in the VKI Plasmatron facility has low Reynolds numbers. The finite thickness boundary-layer model is more appropriate [26] and the approach needs to be adapted to model accurately the flow around the tested sample. This last treatment, detailed below, leads to the definition of the final probe radius that allows duplication of the hypersonic boundary layer in a subsonic plasma wind tunnel.

The flow characteristics at the stagnation line in front of the hemispherical probe in the Plasmatron chamber can be represented using the following five nondimensional parameters (NDPs) defined for a finite thickness boundary layer, which can be given as [26]

$$
\mathrm{NDP} 1=\frac{\delta_{\mathrm{FT}}}{R_{m}}
$$
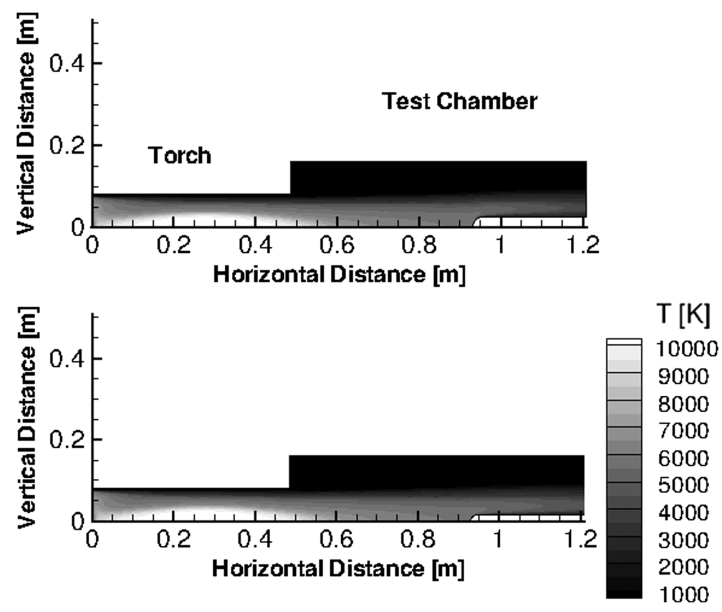

Fig. 9 Subsonic plasma temperature field in Plasmatron chamber computed by ICP with two different probes of $25 \mathrm{~mm}$ (top) and $15 \mathrm{~mm}$ (bottom) radius at $6180 \mathrm{~Pa}$ and $95 \mathrm{~kW}$ power.

$$
\begin{gathered}
\mathrm{NDP} 2=\frac{\partial u}{\partial x} \cdot \frac{R_{m}}{v_{s}} \\
\mathrm{NDP} 3=\frac{R_{m}^{2}}{v_{s}} \cdot \frac{\partial}{\partial y}\left(\frac{\partial u}{\partial x}\right) \\
\mathrm{NDP} 4=\frac{v\left(\delta_{\mathrm{FT}}\right)}{v_{s}} \\
\mathrm{NDP} 5=\frac{v\left(\delta_{\mathrm{FT}}\right)}{v_{e}}
\end{gathered}
$$

where the reference frame and the variables depicted in Fig. 1 are used. The $R_{m}$ value corresponds to the radius of the cylindrical afterbody of the probe. This is also the nose radius when a hemispherical probe is used.

Considering the $x$-momentum equation at the finite thickness boundary-layer edge where the external inviscid flow and the boundary layer are matched,

$$
\frac{\partial p}{\partial x}=-\rho u \cdot \frac{\partial u}{\partial x}-\rho v_{e} \cdot \frac{\partial u}{\partial y}
$$

and equating this pressure gradient to the one at the inviscid wall, where $v=0$, introduces directly $R_{\text {eff }, S}$ using the definitions given in Eqs. (13-17) as a function of NDPs and the model radius $R_{m}$ :

$$
\begin{gathered}
R_{\mathrm{eff}, S}=\frac{R_{m}}{\mathrm{NDP} 2\left(1+\left[(\mathrm{NDP} 5 \cdot \mathrm{NDP} 3) / \mathrm{NDP}^{2}\right]\right)} \\
R_{\mathrm{eff}, S}=\frac{R_{m}}{f(\mathrm{NDP})}
\end{gathered}
$$

One can now compute an $R_{m}$ with the function of NDPs that comes from solving the flow in Plasmatron by the ICP code with an initial guess of a hemispherical probe geometry of $R_{m, \text { guessed }}$. It should be noted that, even if the $R_{\text {eff, } S}$ is given, the NDP2 and NDP3 are functions of $R_{m}$. So Eq. (20) should be solved iteratively as there is no closed-form solution to $R_{m}$.

\section{Results and Discussion}

For testing the procedure, the boundary-layer profile in front of this hemispherical probe in Plasmatron was computed for the new probe geometry by using the finite thickness BL solver NEBOULA [26]. The finite boundary-layer thicknesses come from the new probe geometry (all NDPs) but the edge conditions come from hypersonic CFD for QARMAN geometry or the hypersonic flying sphere with $R_{\text {eff }, H}$ that are equivalent by definition of LHTS.

\section{A. Part 1: QARMAN Geometry to Hypersonic Equivalent Sphere}

As described in Part 1, the definition of the hypersonic equivalent spherical radius of QARMAN requires the definition of the velocity gradient $\beta$ at the boundary-layer edge. The choice of defining the boundary-layer edge location as the point where the temperature profile stops to be linear has been already discussed. Figure 10 shows computed velocity gradients along the stagnation line of Q $\overline{\mathrm{AR}} \mathrm{MAN}$ for cases of both viscous and inviscid flow together with the temperature profile of the viscous case only (simulations are performed with VKI Stagnation Line Code [43]). It is interesting to note that this boundary-layer edge location defined on the basis of the temperature profile agrees very well with the deviation point of the two velocity gradients. This behavior confirms the analogy between the kinetic and the thermal boundary layer in the actual hypersonic conditions [31].

Once the boundary-layer edge has been defined, the $R_{\text {eff } H}$ value can be easily computed from Eq. (4) using the value of $\beta$ obtained from the viscous simulation. This computation returns an $R_{\text {eff. } H}$ value 


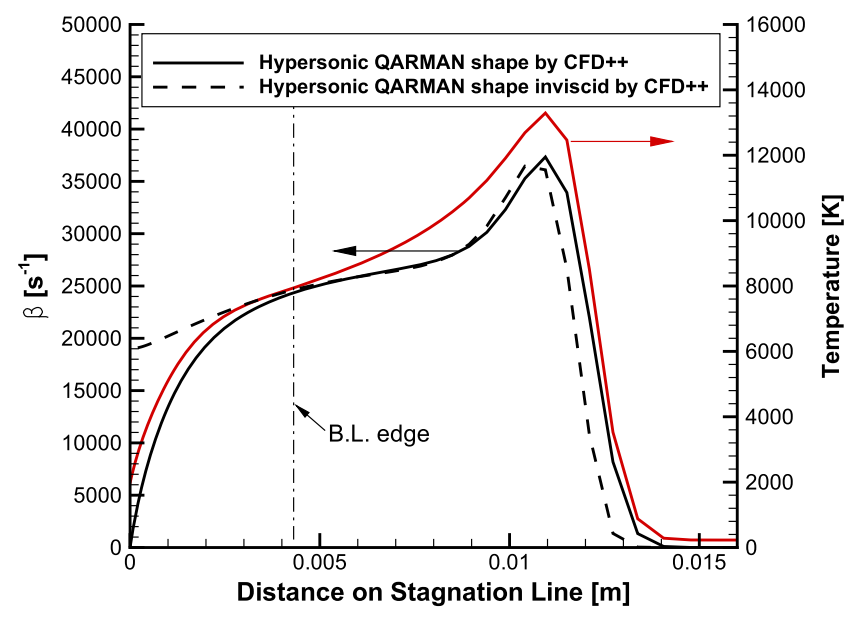

Fig. 10 Viscous and inviscid stagnation-line velocity gradient profile, and temperature profile in the case of viscous flow for the QARMAN shape for conditions at $66 \mathrm{~km}$ altitude.

of $12.4 \mathrm{~cm}$. This value has been considered suitable for the next step in the procedure. The uncertainty on these values is later investigated in Sec. V.D.

\section{B. Part 2: Hypersonic Equivalent Sphere to Subsonic Equivalent Sphere}

To apply Eq. (12), one needs to know dynamic and static pressure in the ground facility. Static pressure is directly taken from the trajectory data and the facility is operated in the same condition. The dynamic pressure is a parameter that depends on the free stream values including enthalpy as it appears from LHTS. Finding the correct combination of enthalpy (power) and pressure for operating the plasma wind tunnel requires additional experimental campaigns where the dynamic pressure is measured. The errors on enthalpy and pressure measurements are addressed in the sensitivity analysis in Sec. V.D.

Combined with the experimental campaign in VKI Plasmatron, the hypersonic effective radius for $66 \mathrm{~km}$ altitude returns a subsonic sphere radius of $8.31 \mathrm{~mm}$. It is important to note that there is no assumption concerning the used boundary-layer model until this step; therefore, this radius remains computed with the classical boundary-layer model, adapted for high-enough Re numbers.

\section{Parts 3-4: Subsonic Equivalent Sphere to Model Geometry and Iteration}

To change the boundary-layer model from classical to finite thickness formulation, thus converting the subsonic equivalent radius to the probe model, the test chamber flow has to be computed by the ICP code [8]. The inputs for the ICP code are exactly the same as the operating parameters of the plasma wind tunnel.

For subsonic plasma test conditions corresponding to the trajectory point of $66 \mathrm{~km}$, an educated guess of $R_{m \text {, guessed }}$ is used to run an ICP computation of the chamber. Because a hemispherical probe will be used, the first guess was $R_{m \text {,guessed }}=25 \mathrm{~mm}$. The solution for this probe is depicted in Fig. 9 (top). Then the process is iterated until the $R_{m \text {,found }}$ through Eq. (19) is the same as the $R_{m \text {,guessed }}$ with which ICP code is rerun and from where the NDPs are extracted. For this condition, the $R_{m}$ is converged to $10.52 \mathrm{~mm}$ (closer to the one in

Table 1 NDPs for the

\begin{tabular}{lc}
\multicolumn{2}{c}{ converged $\boldsymbol{R}_{\boldsymbol{m}} \mathbf{1 0 . 5 2} \mathbf{~} \mathbf{m}$} \\
\hline \hline NDPs & Value \\
\hline NDP1 & 0.2984 \\
NDP2 & 0.2520 \\
NDP3 & 0.6410 \\
NDP4 & 0.2654 \\
NDP5 & 0.4011 \\
\hline \hline
\end{tabular}

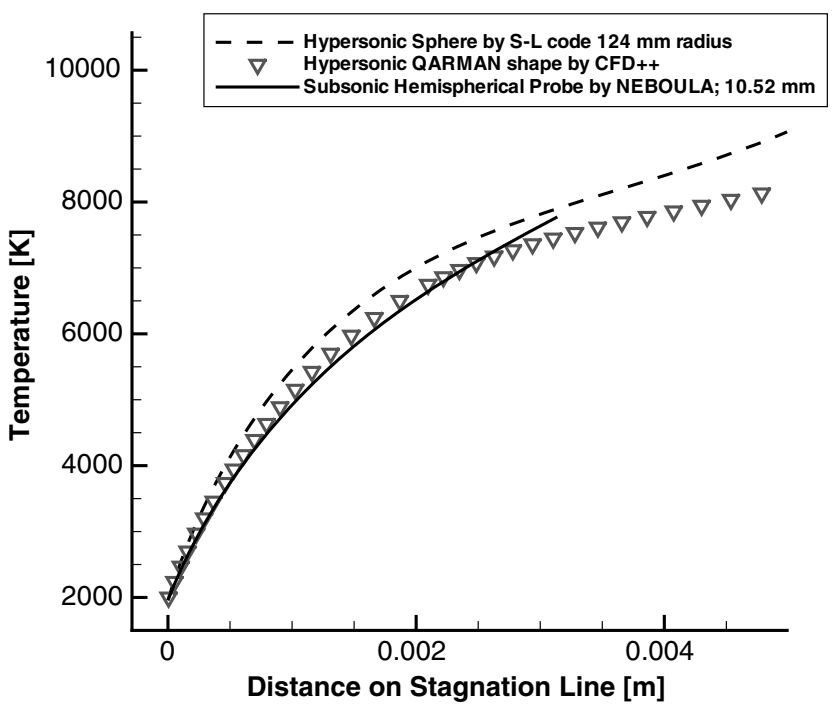

Fig. 11 Temperature along stagnation line. Comparison of the squared hypersonic QARMAN CFD, the hypersonic equivalent sphere CFD, and the hemispherical model in subsonic plasma for $66 \mathrm{~km}$ conditions.

Fig. 9 bottom). For Pressure ${ }_{\mathrm{ICP}}=6180.27 \mathrm{~Pa}$ and Power $_{\mathrm{ICP}}=$ $95 \mathrm{k} \overline{\mathrm{W}}$ (which is the net power going into plasma), the NDPs are given in Table 1 .

From the ICP computation, $f(\mathrm{NDP})$ changes with the geometry and the flow conditions; however, the change is around $6-7 \%$ for $40 \%$ change in guessed radius, which makes the iteration process rather fast and easy.

The boundary-layer flow properties of the newly defined hemispherical probe are solved by the in-house NEBOULA code, which computes finite thickness boundary-layer equations [26]. The change in the boundary-layer model is automatically introduced by the NDP1 given in Eq. (13).

Figures 11 and 12 show the result of the iterative procedure in terms of temperature and density distributions on the stagnation line. One can see that there is a very good agreement with each step of the procedure. As can be seen in Fig. 11, there is a 4\% difference around the boundary-layer edge of the hypersonic sphere solution and the hypersonic QARMAN solution. However, it should be noted that this procedure aims to test the in-flight experiments and the TPS of spacecraft. Higher slope of temperature means that the heat flux is slightly higher and this leads to a considerably conservative approach.

One can also see that the flow in front of the hemispherical probe in Plasmatron conditions shows a very good agreement close to the wall for both temperature and density. This is a driving parameter for the heat flux and the chemistry at the stagnation region. Therefore, it can be concluded that the procedure provides a good duplication of the boundary layer at the stagnation region.

A very interesting outcome is to see how much the geometry is changing from the actual hypersonic vehicle to the probe geometry to be used in a subsonic plasma facility. The original QARMAN shape had a square cross section of $10 \times 10 \mathrm{~cm}^{2}$, while the equivalent geometry to be put in the subsonic plasma test facility is a $10.52-\mathrm{mm}$ radius hemispherical probe. The changes in geometrical parameters are sketched to scale in Fig. 13.

\section{Sensitivity Analysis}

The sensitivity analysis is done on the same trajectory point at $66 \mathrm{~km}$ of altitude as described in the previous section. First, the error sources are determined for each step. The errors of the validated numerical codes (CFD++, Stagnation Line Code, ICP, and NEBOULA), the error of atmospheric model for $p_{\infty}, \rho_{\infty}, p_{0}$ values used in trajectory analysis, and the 7-species air model are neglected. The considered error sources are summarized in Table 2 . It is seen that there are three major error contributions and each is assigned an error applied to the nominal value, resulting three values per parameter. To 
keep the sensitivity analysis simple, out of the nine values computed at each step, the minimum, nominal, and maximum values are taken to the next step. Each of these values and the assigned errors are specified in Table 2 .

The first one is the $\beta$ pick-up location $\delta$, which is the point where the temperature profile stops to be linear. This point can be determined by the derivative along the stagnation line and a $10 \%$ error is assigned on the $\delta$ location toward the wall and away from the wall. The main parameters that are directly affected by $\delta$ are the computed $R_{\mathrm{eff}, H}$ and the boundary conditions $\left(h_{e}, \rho_{e}, T_{e}, \mu_{e}\right)$ given at the boundary-layer edge to NEBOULA at the last step where the model geometry profiles are compared with QARMAN. The effect of the pick-up location is isolated by fixing the rest of the parameters ( $\sqrt{p_{e} \Delta p}$ and power).

The second term is the effect of pressure measurement errors $\sqrt{p_{e} \Delta p}$ on the calculation of $R_{\text {eff }, S}$ that appears in Eq. (12). Its effect is isolated by fixing the pick-up location and the Plasmatron power and by using the minimum, nominal, and maximum values given in Table $\underline{2}$ for simplification. This is the largest effect among all three sources.

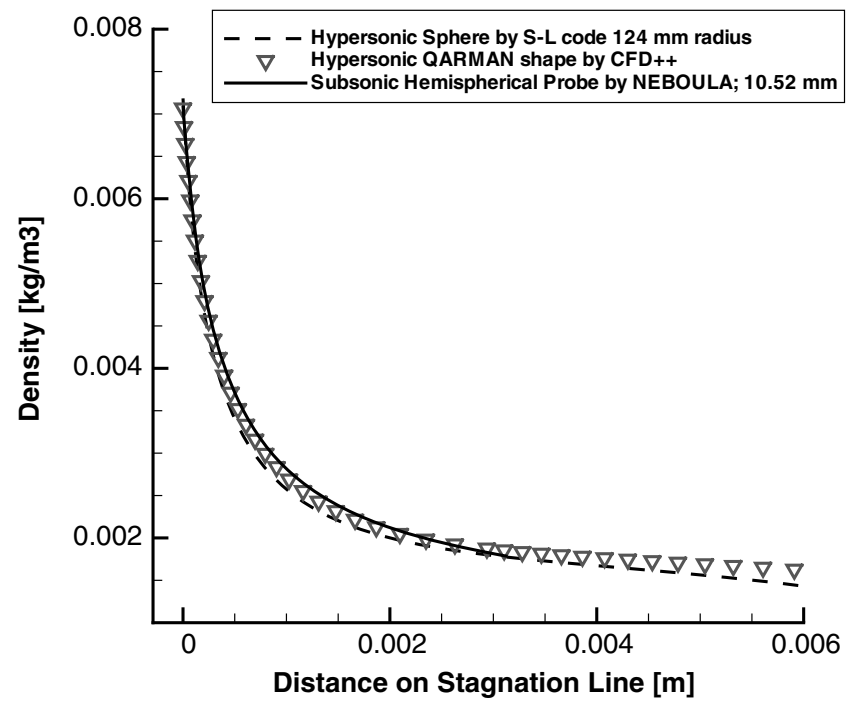

Fig. 12 Density along stagnation line. Comparison of the squared hypersonic QARMAN CFD, the hypersonic equivalent sphere CFD, and the hemispherical model in subsonic plasma for $66 \mathrm{~km}$ conditions.

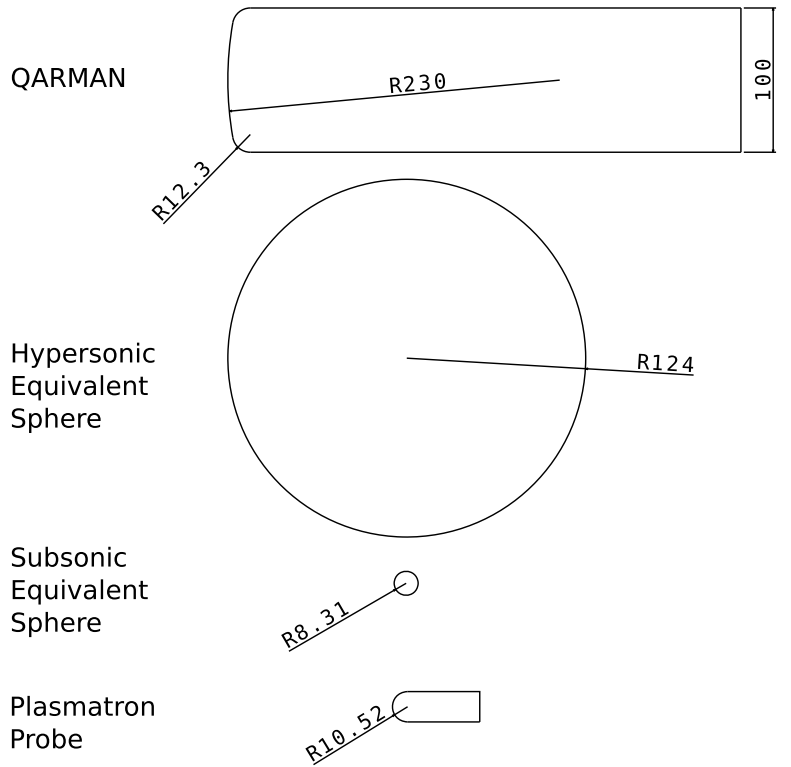

Fig. 13 Change in geometrical parameters in millimeters at each step of the flight-to-ground duplication methodology.
Table 2 Error sources affecting the converged $R_{m}$ solution and their assigned values

\begin{tabular}{|c|c|c|c|c|}
\hline Step & Uncertainty source & $\begin{array}{c}\text { Affected } \\
\text { term }\end{array}$ & Uncertainty $^{\mathrm{a}}$ & $\overline{R_{m} / R_{m}{ }^{\mathrm{b}}}$ \\
\hline \multirow[t]{2}{*}{$\begin{array}{l}\text { Vehicle } \\
\text { shape } \\
\text { to } R_{\mathrm{eff}, H}\end{array}$} & $\begin{array}{l}\text { Velocity gradient } \\
\text { pick-up location: } \\
\text { boundary-layer edge }\end{array}$ & $\beta$ & $-10 \%$ to $\bar{\delta}$ & 1.02 \\
\hline & & & $+10 \%$ to $\bar{\delta}$ & 0.99 \\
\hline \multirow[t]{2}{*}{$\begin{array}{l}R_{\text {eff, } H} \\
\text { to } R_{\text {eff, } S}\end{array}$} & $\begin{array}{l}\text { Ground test } \\
\text { measurements }\end{array}$ & $\sqrt{p_{e} \Delta p}$ & $\begin{array}{l}-2 \% \text { to } \overline{P_{e}} \\
-15 \% \text { to } \overline{\Delta p}\end{array}$ & 0.89 \\
\hline & & & $\begin{array}{l}+2 \% \text { to } \overline{p_{e}} \\
+15 \% \text { to } \overline{\Delta p}\end{array}$ & 1.11 \\
\hline \multirow[t]{2}{*}{$\begin{array}{l}R_{\text {eff }, S} \\
\text { to } R_{m}\end{array}$} & $\begin{array}{l}\text { Plasmatron } \\
\text { power (Pwr.) }\end{array}$ & $f(\mathrm{NDP})$ & $-11 \%$ to $\overline{\mathrm{Pwr}}$ & 0.99 \\
\hline & & & $+11 \%$ to $\overline{\text { Pwr. }}$ & 1.01 \\
\hline
\end{tabular}

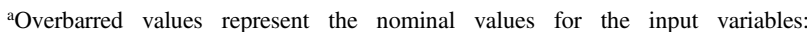
$\bar{\delta}=4.28 \mathrm{~mm}, \overline{P_{e}}=6180.2 \mathrm{~Pa}, \overline{\Delta P}=26.01 \mathrm{~Pa}$, and $\overline{P w r} .=95 \mathrm{~kW}$.

${ }^{\mathrm{b}}$ Nominal value for the final quantity of interest is $\overline{R_{m}}=10.52 \mathrm{~mm}$

The last term is the power of Plasmatron facility that not only affects the $f$ (NDP) computed by the ICP code but also drives the boundary-layer edge enthalpy in the facility because the free stream enthalpy is adjusted by power. The power margin to be imposed in ICP computation is deduced from the enthalpy uncertainty through the experimental database. It corresponds to $11 \%$ margin on the nominal power of $95 \mathrm{~kW}$, which gives $h_{e}=23.57 \mathrm{~kJ} / \mathrm{kg}$ at the reference condition. This margin includes the QARMAN trajectory condition at $66 \mathrm{~km}$ that has an enthalpy of $23.43 \mathrm{~kJ} / \mathrm{kg}$. By fixing the pick-up location and the pressure terms to nominal, the effect of power on the $R_{m}$ and temperature profiles is found to be smaller than the previous sources as shown in Table 2 .

How the combination of different error source terms affects the temperature profiles is also investigated. The highest extreme case is found to be the combination of $\bar{\delta}+10 \%$ location, $R_{\text {eff.S.min }}$, and the highest power of $105 \mathrm{~kW}$ leading to $R_{m}=9.45 \mathrm{~mm}$. Additionally, the lowest extreme case is the combination of $\bar{\delta}-10 \%$ location, $R_{\text {eff, } S \text { max }}$, and the lowest power of $85 \mathrm{~kW}$ leading to $R_{m}=$ $11.68 \mathrm{~mm}$. These two extremes are plotted in Fig. 14 together with the nominal case and QARMAN CFD. These extremes are considered as the total interval of the uncertainty. Taking the maximum deviation, the uncertainty on the final model radius is $R_{m}=10.52 \pm 1.2 \mathrm{~mm}$.

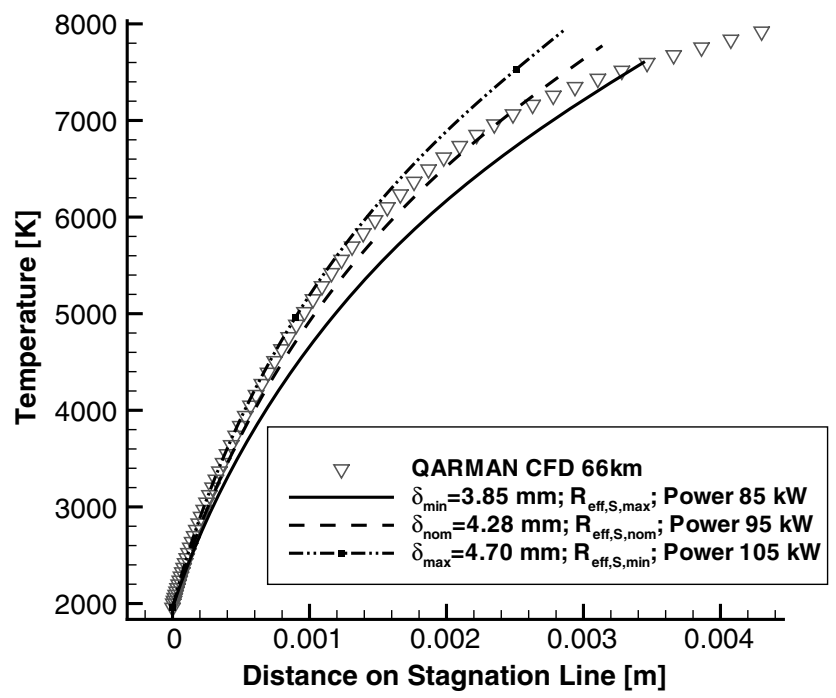

Fig. 14 Combination of errors with the extreme high values. The lowest temperature case has $R_{m}=11.68 \mathrm{~mm}$, the nominal case $R_{m}=10.52 \mathrm{~mm}$, and the highest temperature $R_{m}=9.45 \mathrm{~mm}$. 


\section{Conclusions}

A methodology of accurate ground testing for any spacecraft geometry including nonaxisymmetry and bluntness is presented. To make a suitable flight-to-ground duplication, one has to determine accurately the flow conditions and the test probe geometry in the ground facility because the full simulation rule is to duplicate the pressure, enthalpy, and the velocity gradient at the boundarylayer edge.

The iterative methodology includes the passage from an arbitrary hypersonic vehicle geometry to its "hypersonic equivalent sphere," then to a "subsonic equivalent sphere" for subsonic plasma, and finally to the probe geometry where the thermal protection systems and the instrumentation of the spacecraft can be tested. The ground facility type under investigation is a subsonic plasma wind tunnel, the von Karman Institute Plasmatron.

The test case of QubeSat for Aerothermodynamic Research and Measurements on AblatioN (QARMAN) is presented. The procedure is applied to its trajectory at $66 \mathrm{~km}$ altitude. The flow fields along the stagnation line of the hypersonic vehicle, the hypersonic equivalent sphere, and the hemispherical probe for ground testing are compared and are shown to have a good agreement. The ground testing duplication, presented for QARMAN as a preflight analysis, is applicable to any spacecraft without a limitation on its geometry.

Using the flight data, obtained from QARMAN mission or other available flight data package, the study could be carried out further along with the postflight analysis. Starting from the actual flight data, the proposed flight-to-ground duplication could be applied to define the corresponding plasma wind tunnel testing conditions as it has been presented in this paper. The ground testing data, relative to a specific trajectory point, would be compared with the temperature, heat flux, recession, and material response data from the flight.

\section{Acknowledgments}

Research of Alessandro Turchi is sponsored by the European Research Council Starting Grant \#259354 of Thierry E. Magin. The authors are grateful to Pascal Collin for his unique dedication to the operation of the VKI Plasmatron facility, to Thorsten Scholz for the hypersonic QARMAN CFD computations, and to Damien Le Quang Huy for spectroscopic measurements.

\section{References}

[1] Sakraker, I., Umit, E., van der Haegen, V., and Chazot, O., "Atmospheric Entry Aerothermodynamics Flight Test on CubeSat Platform," 11th International Planetary Probe Workshop, Pasadena, CA, June 2014, Paper 214.

[2] The CubeSat Program, Cal Poly SLO, "CubeSat Design Specification, Revision 13," Issued Jan. 20 2014, http://www.cubesat.org/images/ developers/cds_rev13_final.pdf [retrieved 1 July 2015].

[3] Fay, J. A., and Riddell, F. R., "Stagnation Point Heat Transfer in Dissociated Air Flow," Journal of the Aeronautical Sciences, Vol. 25, 1958, No. 2, pp. 73-85.

[4] Lees, L., "Laminar Heat Transfer over Blunt Nosed Bodies at Hypersonic Flight Speeds," Jet Propulsion, Vol. 26, No. 4, 1958, pp. 497-499.

[5] Goulard, R., "On Catalytic Recombination Rates in Hypersonic Stagnation Heat Transfer," Jet Propulsion, Vol. 28, No. 11, 1958, pp. 737-745 doi:10.2514/8.7444

[6] Kolesnikov, A., "Extrapolation from High Enthalpy Tests to Flight Based on the Concept of Local Heat Transfer Simulation," RTO AVT Course on Measurement Techniques for High Enthalpy and Plasma Flows, NATO Science and Technology RTO-EN-8, Brussels, 1999, pp. 8B,1-14

[7] Anderson, J. D., "Hypersonic and High Temperature Gas Dynamics," McGraw-Hill, Boston, 2000, p. 299

[8] Degrez, G., Vanden Abeele, D. P., Barbante, P., and Bottin, B., "Numerical Simulation of Inductively Coupled Plasma Flows Under Chemical Non-Equilibrium," International Journal of Numerical Methods for Heat \& Fluid Flow, Vol. 14, No. 4, 2004, pp. 538-558. doi:10.1108/09615530410532286
[9] Panerai, F., "Aerothermochemistry Characterization of Thermal Protection Systems," Ph.D. Thesis, Universite degli Studi di Perugia and von Karman Inst. for Fluid Dynamics, Rhode-Saint-Genese, Belgium, 2012.

[10] Guelhan, A., Esser, B., Del Vecchio, A., Loehle, S., Sauvage, N. Chazot, O., and Asma, C. O., "Comparative Heat Flux Measurements on Standard Models in Plasma Facilities," 13th International Space Planes Conference, AIAA Paper 2005-3324, June 2005.

[11] Barbante, P. F., and Chazot, O., "Flight Extrapolation of Plasma Wind Tunnel Stagnation Region Flowfield," Journal of Thermophysics and Heat Transfer, Vol. 20, No. 3, 2006, pp. 493-499. doi: $10.2514 / 1.17185$

[12] Boison, J. C., and Curtiss, A. C., "An Experimental Investigation of Blunt Body Stagnation Point Velocity Gradient," ARS Journal, Vol. 29, No. 2, 1959, pp. 130-135. doi: $10.2514 / 8.4699$

[13] Trimmer, L. L., and Clark, E. L., "Stagnation-Point Velocity Gradients for Spherical Segments in Hypersonic Flow," AIAA Journal, Vol. 7, No. 10,1969 , pp. $2040-2041$ doi: $10.2514 / 3.5511$

[14] Fletcher, D. G., and Playez, M., "Characterization of Supersonic and Subsonic Plasma Flows," 25th AIAA Aerodynamic Measurement Technology and Ground Testing Conference, AIAA Paper 2006-3294, June 2006

[15] White, F. M., "Viscous Fluid Flow," Vol. 3, McGraw-Hill, New York, 1991.

[16] Lunev, V., "Hypersonic Aerodynamics, Mashinostroyeniye, Moscow, 1975 (in Russian)".

[17] Olivier, H., "Influence of the Velocity Gradient on the Stagnation Point Heating in Hypersonic Flow," Shock Waves, Vol. 5, No. 4, 1995, pp. 205-216. doi:10.1007/BF01419002

[18] Hayes, W. D., and Probstein, R. F., "Hypersonic Flow Theory," Academic Press, London, U.K., 1959, p. 191.

[19] Lees, L., "Recent Developments in Hypersonic Flow," Journal of Jet Propulsion, Vol. 27, No. 11, 1957, pp. 1162-1178. doi:10.2514/8.12491

[20] Zoby, E. V., and Sullivan, E. M., "Effects of Corner Radius on Stagnation-Point Velocity Gradients on Blunt Axisymmetric Bodies," NASA TM-X-1067, 1967.

[21] Ellison, J. C., "Experimental Stagnation Point Velocity Gradients and Heat Transfer Coefficients for a Family of Blunt Bodies at Mach 8 and Angles of Attack," NASA Langley TN-D-5121, 1969.

[22] Zoby, E. V., "Empirical Stagnation Point Heat Transfer Relation in Several Gas Mixtures at High Enthalpy Levels," NASA Langley TN-D4799, 1968.

[23] Loehle, S., Brandis, A., Hermann, T., and Peter, J., "Numerical Investigation of the Re-Entry Flight of Hayabusa and Comparison to Flight and Ground Testing Data," 43rd AIAA Thermophysics Conference, AIAA Paper 2012-3102, June 2012.

[24] Prabhu, D., "Flowfield Analysis of a Small Entry Probe (SPRITE) Tested in an Arc Jet," 50th AIAA Aerospace Sciences Meeting Including the New Horizons Forum and Aerospace Exposition, AIAA Paper 2012-0216, Jan. 2012

[25] Bottin, B., "Aerothermodynamic Model of an Inductively-Coupled Plasma Wind Tunnel," Ph.D. Thesis, Universite de Liege and von Karman Institute for Fluid Dynamics, Rhode-Saint-Genese, Belgium, Oct. 1999.

[26] Barbante, P. F., "Accurate and Efficient Modelling of High Temperature Nonequilibrium Air Flows," Ph.D. Thesis, Universite Libre de Bruxelles and von Karman Institute for Fluid Dynamics, Rhode-Saint-Genese, Belgium, 2001.

[27] Villedieu, N., Panerai, F., Chazot, O., and Magin, T. E., "Uncertainty Quantification for Gas-Surface Interaction in Plasmatron Facility," 7th European Symposium on Aerothermodynamics, ESA SP-692, Noordwijk, The Netherlands, May 2011.

[28] Nawaz, A., Driver, D. M., Terrazas-Salinas, I., and Sepka, S., "Surface Catalysis and Oxidation on Stagnation Point Heat Flux Measurements in High Enthalpy Arc Jets," 44th AIAA Thermophysics Conference, AIAA Paper 2013-3138, June 2013.

[29] Griem, H. R., Principles of Plasma Spectroscopy, Cambridge Univ. Press, Cambridge U.K., 1997, pp. 173-176.

[30] Le Quang Huy, D., "Spectroscopic Measurements of Sub- and Supersonic Plasma Flows for the Investigation of Atmospheric Re-Entry Shock Layer Radiation," Ph.D. Thesis, Universite Blaise Pascal and von Karman Institute for Fluid Dynamics, Rhode-Saint-Genese, Belgium, 2014.

[31] Schlichting, H., and Gersten, K., "Boundary Layer Theory," 5th ed., Springer, Heidelberg, 1979, p. 127. 
[32] Park, C., "Radiation Enhancement by Nonequilibrium in Earth's Atmosphere," Journal of Spacecraft and Rockets, Vol. 22, No. 1, 1985, pp. 27-36. doi: $10.2514 / 3.25706$

[33] Turchi,, A., Matesanz Saiz, J. J., Magin, T. E., and Chazot, O., "On the Flight Extrapolation of Stagnation-Point Ablative Material Plasma Wind Tunnel Tests," Proceedings of 8th European Symposium on Aerothermodynamics for Space Vehicles, ESA, Noordwijk, The Netherlands, March 2015.

[34] Landau, L., and Lifchitz, E., "Physique Theorique Tome 6: Mecanique des Fluides," Editions MIR, Moscow, 1989, Chap. 1.

[35] Chazot, O., Regnier, R., and Garcia Munoz, A., "Simulation Methodology in Plasmatron Facility and Hypersonic Wind Tunnels," Proceedings of 12th International Conference on Method of Aerophysical Research - Part IV, Akademgorodok, Novosibirsk, Russia, JuneJuly 2004 (to be published in the CEAS Space Journal, 2016).

[36] Horton, T. E., and Babineaux, T. L., "Influence of Atmosphere Composition on Hypersonic Stagnation-Point Convective Heating," AIAA Journal, Vol. 5, No. 1, Jan. 1967, pp. 36-43. doi: $10.2514 / 3.3904$

[37] Yee, L., Bailey, H. E., and Woodward, H. T., "Ballistic Range Measurements of Stagnation-Point Heat Transfer in Air and in Carbon Dioxide at Velocities up to 18,000 Feet Per Second," NASA TN-D-777, 1961.

[38] Rose, P. H., and Stark, W. I., "Stagnation-Point Heat Transfer Measurements in Dissociated Air," Journal of the Aerospace Sciences,
Vol. 25, No. 2, Feb. 1958, pp. 86-97. doi: $10.2514 / 8.7519$

[39] Rose, P. H., and Stankevics, J. O., "Stagnation-Point Heat Transfer Measurements in Partially Ionized Air," AIAA Journal, Vol. 1, No. 12, Dec. 1963, pp. 2752-2763. doi: $10.2514 / 3.2169$

[40] Zuppardi, G., and Esposito, A., "Recasting the Fay-Riddell Formulae for Computing the Stagnation Point Heat Flux," Proceedings of the Institution of Mechanical Engineers, Vol. 214, No. 2, Part G, 2000, pp. 115-120. doi: $10.1243 / 0954410001531863$

[41] Sagnier, P., and VÂl'rant, J.-L., "Flow Characterization in the ONERA F4 High-Enthalpy Wind Tunnel," AIAA Journal, Vol. 36, No. 4, April 1998, pp. 522-531. doi: $10.2514 / 2.425$

[42] De Fillipis, F., and Serpico, M., "Air High Enthalpy Stagnation Point Heat Flux Calculation,” CIRA TN-96-014, Jan. 1996.

[43] Munafo, A., "Multi-Scale Models and Computational Methods for Aerothermodynamics," Ph.D. Thesis, Ecole Centrale Paris and von Karman Institute for Fluid Dynamics, Rhode-Saint-Genese, Belgium, 2014.
A. Dufrene

Associate Editor 